\title{
PRUDENT DECISIONS TO ESTIMATE THE RISK OF LOSS IN INSURANCE
}

\author{
Casian BUTACI ${ }^{\mathrm{a}}$, Simona DZITAC ${ }^{\mathrm{b}}$, Ioan DZITAC ${ }^{\mathrm{a}, \mathrm{c}}$, Gabriela BOLOGA $^{\mathrm{a}}$ \\ ${ }^{a}$ Department of Social Sciences, Faculty of Economics, Agora University of Oradea, \\ Piata Tineretului 8, RO-485526 Oradea, Romania \\ ${ }^{b}$ Department of Energy Engineering, Faculty of Energy Engineering and Industrial Management, \\ University of Oradea, Universitatii st. 1, RO-485526 Oradea, Romania \\ ${ }^{c}$ Deparatment of Mathematics and Informatics, Faculty of Exact Sciences, Aurel Vlaicu \\ University of Arad, Elena Dragoi 2, RO-310330 Arad, Romania
}

Received 1 September 2016; accepted 18 January 2017

\begin{abstract}
The directive 2009/138/EC „Solvency II", provides the determination of insurance capital requirements based either on a standard formula or an internal model built by the company and approved by the regulatory authority. The build of an internal model involves the determination of an extreme quantile from the empirical distribution of portfolio. An estimate of this quantile, with a 99.5\% confidence level, requires a large number of simulations, each taking into account different scenarios as: insufficient reserves, unfavourable developments of financial assets, etc. The present paper proposes to argue the necessity of the extreme value theory approach in order to estimate the risk of loss for the insurance issue, in accordance with European Directive „Solvency II”, from the perspective of making prudent decisions for the assessment of insurance capital requirements.
\end{abstract}

Keywords: solvency, insurance, capital requirement, extreme value, risk of loss, prudential estimation.

JEL Classification: C15, G22.

\section{Introduction}

The strong trend towards the convergence of several fields as insurance, banking and capital markets, together with the common effort to harmonize the regulations in these fields, in the context defined by the IAIS-International Association of Insurance Supervisors, IASBInternational Accounting Standards Board and IAA-International Actuarial Association, have imposed the need to adopt a risk based economic approach that will motivate insurance and reinsurance companies to evaluate and adequately manage risks. Harmonization

Corresponding author Ioan Dzitac

E-mail: rector@univagora.ro 
should be improved by establishing specific norms for the evaluation of assets and liabilities including technical reserves.

Started in 2001, the European project named Solvency II, that is operational since the $1^{\text {st }}$ of January 2016 at the level of all EU insurance firms (according to data given by the European Insurance and Occupational Pensions Authority, EIOPA 2014a, 2014b), has as main objective to regulate the capital requirements in accordance with the risk o loss magnitude, so that the insurance company could avoid solvency for the considered time horizon. Beyond regulations on quantitative requirements (capital adequacy) and the qualitative requirements (financial supervision) new solvency system has proposed to integrate the concept of "market discipline". This last aspect is very important taking into account the continued growth of a cross-border business between insurance companies and the need (Schoenmaker, Sass 2016) to develop methodologies for reporting data to facilitate prudential supervision.

The new European solvency system is embedding the experience of the most important solvability systems from countries as USA, Swiss, Great Britain (Butaci 2014). It is clear that the main novelty brought by this project (EIOPA 2014a, 2014b) is a robust prudential regime achieved by a better correlation between the (re)insurance company risk exposure and solvency capital requirement assigned for risk coverage. From a quantitative point of view this is achieved through a better classification of the risks for the standard risk profile of the (re)insurance company. It is worth to note that on an insurance market characterized y informational asymmetry a better risk classification is increasing the efficiency of monitoring (Keith, Arthur 2013).

On the other hand, trying to obtain an optimal protection level can generate for insurers pretty great costs (Dionne, Li 2011) and in this sense Solvency II considered the increase of the prudential level motivating the companies to fortify their governance system by qualitative increase of the internal process of risk management.

During time, risk management has proved to be efficient in the frame o the governance system (Dionne 2013) due to its capacity to reduce costs associated to the management of different risks. From this point of view, the standard Solvency II regime integrates the benefits of risk diversification, with effects on growth performance and reduction of risk exposure (Chen et al. 2014), and also the possibility of replacing predefined parameters with the company risk parameters that are more appropriate to the firm own risk profile.

The risk of losing the entire insurance company portfolio for a certain time horizon can be modeled by a random variable. From this point of view, the company capital requirement is a probability measure and in function of this measure it is desirable for the insurer to honour in the best possible way commitments he/she made. In other words, the probability that the insurer will not cope with the commitments made (the probability of ruin), for a given time horizon, has to be very small.

The first theoretical developments in the analysis of the probability of ruin are from the beginning of the XX century are due to the well-known Scandinavian actuaries Harald Cramér and Filip Lundberg. The notion of probability of ruin started to be widely used in financing and insurance at the same time with the development of the modern theory of risk measurement. In this theory, the coherent measure of risk conceptualized by Artzner 
(1999) is a point of reference. The use of the concept of risk measure in financial institutions has been lately frequently discussed in literature and we will like to cite the studies Darkiewicz et al. (2003) and Acerbi (2004).

In the field of insurance, based on the theory of the risk measure, a number of approaches have been developed, for pricing insurance contracts (Partrat, Besson 2005) but mainly for determine the capital requirements. These approaches can be found in studies developed by different experts of the field (Cummins 2000; Dhaene et al. 2003, 2004 and recently in Cummins, Philips 2009 and Bauer, Zanjani 2015).

The 2009/138/EC Solvency II Directive stated that the capital requirements have to be determined by a standard formula or by an internal model built by the company and approved by the regulatory authority. In accordance with article 101 of the Solvency II directive, the standard formula for determining the capital requirements is using the measure Value-at-Risk.

The Value-at-risk(VaR) measure is based from a mathematical point of view on the Harry Markowitz (Markowitz 1952, 1959) efficient portfolio theory. The new European solvency system is using this method mainly for simplicity reasons, this being only a quartile with a confidence level of $99.5 \%$. It is known that the VaR measure does not verify the subaditivity propriety and then it cannot integrate very well the diversification effect on the risk of loss reduction, and also cannot integrate the loss severity above the confidence level (Acerbi, Tasche 2001).

Insurance companies will be able to use other risk measures like Tail Value-at-Risk, that offer the advantage of a better solvency capital allocation when developing internal solvency models.

The internal model, designed taking into account all the variables that can influence the solvency of the company, will allow the simulation of the financial situation of the company for a one year horizon and will also offer a measure of the capital requirements needed in order to avoid with a $99.5 \%$ probability the company ruin one year later.

The building of such a model requires determining an extreme quantile from the empirical distribution of the portfolio. In order to obtain an estimation of this quantile, with a $99.5 \%$ confidence level, we need to perform a great number of simulations, each simulation considering a different scenario, as for example: insufficient provision, unfavorable evolution of the financial assets. Basically, in order to evaluate such a quantile we will use techniques specific to the extreme value theory, theory that as been developed in the early '70 by Pickands (1975) and Hill (1975), and by Smith (1987), Dekkers and Haan (1989). These results have been soon applied to financing and insurance by Embrechts et al. (1997). The need to adopt a methodology based on the theory of rare events can be justified (Kunreuther 2015) from the perspective of long-term economic thinking that characterize insurance.

This paper examines from a quantitative point of view the prudencial level captured by the standard formula for determination of the solvency capital requirements as it is introduced by the Solvency II directive. We have also tried to offer a quantitative argument in favor of the use of the extreme value theory for settin te prudential level. In order to achieve our goal we have built a hypothetical investment portfolio and the quantitative research was done on this portfolio. 


\section{Theoretical aspects concerning the extreme quantile}

Applying risk measures in the field of insurance asks for different approaches comparing to banking issues. Banks will always have sufficient statistical data for computing, by example the VaR for a time horizon of 10 days as it is the banking regulation.

In the case of insurance companies, the time horizon for determining the solvency requirements is, in accordance with Solvency II directive, of 250 days and in this case the available statistical data will not be sufficient.

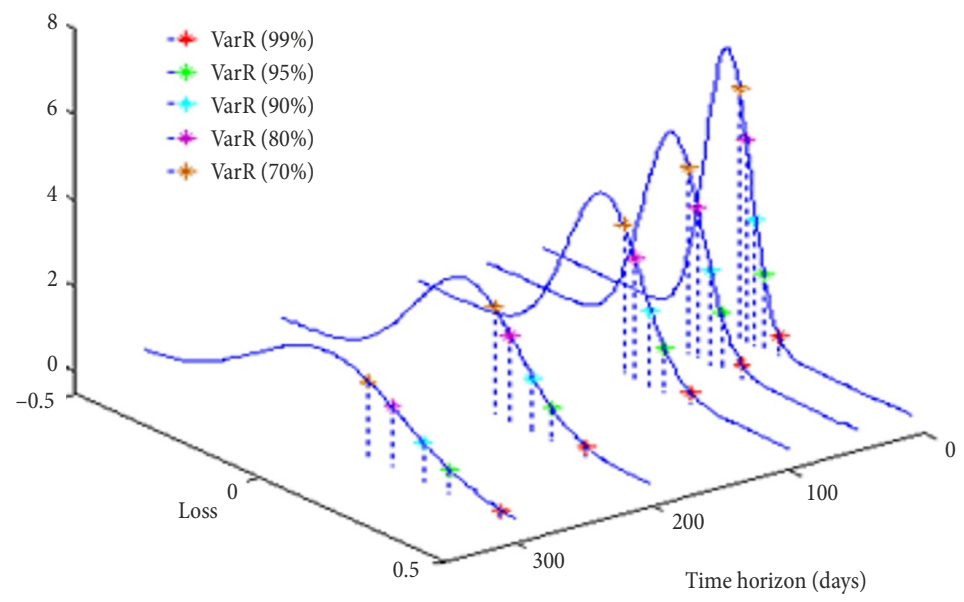

Fig. 1. Representation of the measure VaR in dependence of trust threshold and time horizon

In Figure 1 we can see that the value at risk VaR is moving to the extreme values of the loss distribution as the time horizon is increasing. In this situation in order to determine the value at risk we have to use techniques or adjusting the loss distribution, for example the theory of extreme values.

\subsection{Limit law for the maximum}

Let $\mathrm{X}_{1}, \ldots, \mathrm{X}_{\mathrm{n}}$ be a sample of random variables (for example damages claimed by the insured for a specific time horizon), independent and with the same distribution function F. We will consider also the order statistics associated to the variables: $X_{1: n}, X_{2: n}, \ldots, X_{n: n}$. With these order statistics we can define the minimum and the maximum of the sample of random variables:

$$
\min \left\{\mathrm{X}_{1}, \ldots, \mathrm{X}_{\mathrm{n}}\right\}=\mathrm{X}_{1: \mathrm{n}} \leq \mathrm{X}_{2: \mathrm{n}} \leq \ldots \leq \mathrm{X}_{\mathrm{n}: \mathrm{n}}=\max \left\{\mathrm{X}_{1}, \ldots, \mathrm{X}_{\mathrm{n}}\right\}
$$

The distribution function for the order statistics $\mathrm{X}_{\mathrm{i}: \mathrm{n}}$ is given by (Denuit, Charpentier 2005: 410).

$$
F_{i: n}(x)=\operatorname{Pr}\left(X_{i: n} \leq x\right)=\sum_{j=1}^{n} C_{n}^{j}(F(x))^{j}(1-F(x))^{n-j} .
$$

Based on (1) we can deduce the distribution functions for the extreme values, i.e. 


$$
\begin{gathered}
\mathrm{F}_{1: \mathrm{n}}(\mathrm{x})=1-(1-\mathrm{F}(\mathrm{x}))^{\mathrm{n}} \text { and } \\
\mathrm{F}_{\mathrm{n}: \mathrm{n}}(\mathrm{x})=(\mathrm{F}(\mathrm{X}))^{\mathrm{n}} .
\end{gathered}
$$

The distribution function of the maximum value is explicitly determined by the distribution function of the random variables $X_{1}, \ldots, X_{n}$. This shape of the distribution function of the maximum is not very useful when we want to determine the probability of rare events occurrence.

To show this aspect we will first define the upper boundary of the definition set of the function $F$ as:

$$
\mathrm{x}_{\mathrm{F}}=\sup \{\mathrm{x} \in \mathrm{R} / \mathrm{F}(\mathrm{x})<1\} \leq \infty .
$$

Once the boundary $\mathrm{x}_{\mathrm{F}}$ defined, we have two situations:

i) for any $x<x_{F}$ we have $\lim _{n \rightarrow \infty} \operatorname{Pr}\left(X_{n: n} \leq x\right)=\lim _{n \rightarrow \infty}(F(x))^{n}=0$;

ii) for any $x \geq x_{F}, x_{F}<\infty$ we have $\lim _{n \rightarrow \infty} \operatorname{Pr}\left(X_{n: n} \leq x\right)=\lim _{n \rightarrow \infty}(F(x))^{n}=1$.

These two situations show us the essential motivation of the development of the asymptotic theory of extreme values. We can see that for values that are not greater than the upper boundary, the probability of a rare (unwanted) event occurrence is zero, while in the case of values greater this boundary the occurrence of a rare event is certain. This is why the distribution function of the maximum $\mathrm{F}_{\mathrm{n}: \mathrm{n}}(\mathrm{x})=(\mathrm{F}(\mathrm{X}))^{\mathrm{n}}$ cannot describe the behaviour of the extreme values starting with a specific threshold, and we need to determine an asymptotic limit for the maximum.

In order to determine an asymptotic distribution law for the maximum we can ask ourselves if there is not, as in the case of the sum of the variables, a law of large numbers or a central limit theorem valid in the case of the maximum. In other words, if conveniently normalizing the variable $\mathrm{X}_{\mathrm{n}: \mathrm{n}}$, can we find a law of the limit of the maximum?

We will look for normalization constants $a_{n} \in R$ şi $b_{n}>0$ so that:

$$
\operatorname{Pr}\left(\frac{\mathrm{X}_{\mathrm{n}: \mathrm{n}}-\mathrm{a}_{\mathrm{n}}}{\mathrm{b}_{\mathrm{n}}} \leq \mathrm{x}\right)=\mathrm{F}^{\mathrm{n}}\left(\mathrm{a}_{\mathrm{n}}+\mathrm{b}_{\mathrm{n}} \mathrm{x}\right) \rightarrow \mathrm{G}(\mathrm{x}) \text {, când } \mathrm{n} \rightarrow \infty,
$$

where G(.) is the distribution function of the limit law for the maximum.

The answer for our questions is given by the Fisher-Tippet-Gnedenko theorem (or the extreme value theorem) that is a general result in extreme value theory regarding asymptotic distribution of extreme order statistics. According to this theorem the distribution function, $\mathrm{G}($.$) , of the limit law for the maximum is of the same type (two distribution functions$ $\mathrm{F}_{1}$ and $\mathrm{F}_{2}$ are of the same type if there are the constants $\mathrm{a} \in \mathrm{R}$ and $\mathrm{b}>0$ so that $\mathrm{F}_{1}(\mathrm{x})=$ $\left.\mathrm{F}_{2}(\mathrm{a}+\mathrm{bx}), \mathrm{x} \in \mathrm{R}\right)$ with one of the following three laws of probabilities defined $\mathrm{b}$ their distribution functions:

(i) $G_{1}(x)=\exp \left(-(1+\xi x)^{-1 / \xi}\right)$, for $x \geq-\frac{1}{\xi}$ and $\xi>0$;

(ii) $G_{2}(x)=\exp (-\exp (-x))$, for $x \in R$ and $\xi=0$; 


$$
\text { (iii) } \mathrm{G}_{3}\left(\mathrm{x}=\exp -(1+\xi \mathrm{x})^{-1 / \xi} \text {, for } \mathrm{x} \leq-\frac{1}{\xi} \text { and } \xi<0\right. \text {. }
$$

The distribution laws $\mathrm{G}_{1}(\xi>0), \mathrm{G}_{2}(\xi=0)$ and $\mathrm{G}_{3}(\xi<0)$ correspond to the Fréchet, Gumbel and Weibull distribution laws. Depending of its form, the distribution function $G($.$) is in the (max) domain of attraction of Fréchet \left(G_{1}\right)$, Gumbel $\left(G_{2}\right)$ or Weibull $\left(G_{3}\right)$.

For the three domain of maximum attraction we can exemplify with the following distribution laws used in the modelling of extreme events in insurance:

- Chi2 Student, Pareto from the attraction domain of Fréchet $\left(G_{1}\right)$ (laws with heavy tails);

- Normal, Lognormal, Exponential, Gamma and Weibull from the attraction domain of Gumbel $\left(\mathrm{G}_{2}\right)$ (laws with exponential decreasing tails);

- Beta and Uniform from the attraction domain of Weibull $\left(G_{3}\right)$ (laws with tails with a terminal point).

\subsection{The limit law of excesses over a given threshold}

Another method for analyzing extreme values is the methods of excesses over a given threshold. This method has been introduced by Pickands (1975) and is known POT (Peaks Over Threshold).

Let be a real number u sufficiently great, define as threshold. The methods of excesses over a given threshold consist in approximating the distribution of the random variable $\mathrm{X}$ for those values that exceed the threshold $\mathrm{u}$. In other words, we will study the behaviour of the law of the conditioned variable $\mathrm{X}-\mathrm{u}$, knowing that $\mathrm{X}>\mathrm{u}$. The distribution function of the law of excesses over a give threshold is defined as follows:

$$
\mathrm{F}_{\mathrm{u}}(\mathrm{y})=\mathrm{P}(\mathrm{X}-\mathrm{u}<\mathrm{y} / \mathrm{X}>\mathrm{u}) .
$$

According to Pickands-Balkema-de Haari theorem, this distribution function corresponds to the Pareto generalized distribution law (GPD - Generalized Pareto Distribution) defined as follows:

Definition 2.1. Generalized Pareto Distribution(GPD)

Let $\mathrm{H}_{\xi, \beta}$ be a distribution function defined by

$$
\mathrm{H}_{\xi, \beta}(\mathrm{x})=\left\{\begin{array}{ll}
1-\left(1+\xi \frac{\mathrm{x}}{\beta}\right)^{-1 / \xi}, & \text { daca } \xi \neq 0 \\
1-\exp \left(-\frac{\mathrm{x}}{\beta}\right), & \text { daca } \xi=0
\end{array},\right.
$$

for $\mathrm{x} \geq 0$, if $\xi \geq 0$, respective $0 \leq \mathrm{x} \leq-\frac{1}{\xi}$, if $\xi<0$. This function correspond to the Pareto generalized law with parameters $\xi, \beta$.

The set of random variables that have this distribution law is named $\operatorname{GDP}(\xi, \beta)$. In function of the values of the parameters $(\xi, \beta)$, the GPD law can belong to all three domain of maximum attraction mentioned before. 


\section{Extreme quantile estimation}

\subsection{Empirical estimation}

In insurance, the evaluation of extreme risk implies the study of the events with rare probability of realization. In this case rare events can be associated to the extreme quantile of high order $(99 \%, 99.9 \%, 99.99 \%, \ldots)$. The statistics of order $X_{k: n}, k \in\{1, \ldots, n\}$ is a natural estimator of the $n-(k-1)$ greater value in the loss sequence and we can say that we have a natural estimation of the quantile of order $\mathrm{p} \in(0 ; 1), \mathrm{F}^{-1}(\mathrm{p})$, given $\mathrm{b}$ the value:

$$
\hat{\mathrm{q}}_{\mathrm{p}}=\mathrm{X}_{\mathrm{n}^{*}: \mathrm{n}}+\left(\mathrm{pn}-\mathrm{n}^{*}\right)\left(\mathrm{X}_{\mathrm{n}^{*}+1: \mathrm{n}}-\mathrm{X}_{\mathrm{n}^{*}: \mathrm{n}}\right) \text {, }
$$

where $n^{\star}$ is the entire part of the product pn.

\subsection{Parametric estimator}

In order to build a parametric estimator we have to adjust the loss distribution by a known distribution law or to use a combination of known parametric laws based on the available data history (Planchet, Thérond 2007: 106). It is known that if $\hat{\theta}$ is an estimator obtained by the maximum likelihood estimation of $\theta$ the parameter of the loss distribution, then $\hat{\mathrm{F}}_{\hat{\theta}}^{-1}(\mathrm{p})$ is a maximum likelihood estimator of the $\mathrm{F}_{\theta}^{-1}(\mathrm{p})$ quantile.

\subsection{GPD estimator}

Using Pickands-Balkema-de Haari results we can estimate (Denuit, Charpentier 2005: 439) the extreme quantile $\mathrm{q}_{\mathrm{p}}$ of order $(\mathrm{p})$ defined by the equation:

$$
\mathrm{F}\left(\mathrm{q}_{\mathrm{p}}\right)=\mathrm{p}, \mathrm{cu} 1-\mathrm{p} \leq 1 / \mathrm{n},
$$

where $\mathrm{n}$ is the sample size.

Usually this kind of quantile is beyond the maximum value observed $\mathrm{X}_{\mathrm{n}: \mathrm{n}}$. For this reason to determine it we use techniques specific to the theory of extreme value. For a threshold sufficiently high $u_{p}$, the distribution $F_{u}$ of the values greater than $u_{p}$ can be approximated by a generalized Pareto distribution (GPD). Based on this adjustment, we can calculate the extreme quantile from (2):

$$
\hat{\mathrm{q}}_{\mathrm{p}}=\mathrm{u}_{\mathrm{p}} \frac{\hat{\xi}}{\hat{\beta}}\left(\left(\frac{\mathrm{n}(1-\mathrm{p})}{\mathrm{N}_{\mathrm{u}}}\right)^{-\hat{\mathrm{i}}}-1\right),
$$

where $N_{u}$ is the number of values greater than the threshold $u_{p}$, and $\hat{\xi}$ and $\hat{\beta}$ are the estimates of the parameters of the distribution law GPD.

For example, if we chose a threshold $u_{p}=X_{n-k: n}$ (the quantile $X_{n-k: n}$ can be of order 99\%) in order to estimate one of the quantile that is greater than this threshold, the number of values greater than the threshold is $\mathrm{N}_{\mathrm{u}}=\mathrm{k}$, and (2) becomes:

where $\mathrm{k}>\mathrm{n}(1-\mathrm{p})$.

$$
\hat{\mathrm{q}}_{\mathrm{p}}=\mathrm{X}_{\mathrm{n}-\mathrm{k}: \mathrm{n}}+\frac{\hat{\xi}}{\hat{\beta}}\left(\left(\frac{\mathrm{n}(1-\mathrm{p})}{\mathrm{k}}\right)^{-\hat{\xi}}-1\right),
$$


In practice, we can determine the estimators for the GPD distribution law parameters, $\hat{\xi}$ and $\hat{\beta}$, by different methods as the maximum likelihood (MLE), probability weighted moment (PWM) (Hosking, Wallis 1987), the Hill methods, the generalized Hill method (HillG), etc.

In using the GDP for quantile estimation we have the problem of choosing the threshold $u_{p}$. The threshold has to be sufficiently great to allow a good approximation though the GPD estimator, but it must not be too close to the quantile $q_{p}$ we are estimating, for not affecting the estimation accuracy.

\subsection{Hill estimator}

If the loss repartition function belongs to the Fréchet $\left(G_{1}\right)$ maximum attraction domain, i.e. $\xi>0$, then the extreme quantile of order (p) can also be estimated (Denuit, Charpentier 2005: 441) by:

$$
\hat{\mathrm{q}}_{\mathrm{p}}^{\mathrm{H}}=\mathrm{X}_{\mathrm{n}-\mathrm{k}: \mathrm{n}}\left(\frac{\mathrm{n}}{\mathrm{k}}(1-\mathrm{p})\right)^{-\hat{\xi}_{\mathrm{H}}},
$$

where $X_{n-k: n}$ is the threshold and $(k)$ is the number of values that passes the threshold.

\section{Prudent estimation decisions}

In this section we are analyzing the need of applying specific techniques of the theory of extreme value to estimation of extreme quantiles.

We have built (Table 1) a hypothetical investment portofolio, that preserves the weight balanced between bonds and shares, specific especially to investment programs like unitlinked that insurance companies are frequently deploying after the conclusion of life insurance policies. This kind of portfolio can be characterized as being moderate loss risk exposure portfolios. Data history is of $\mathrm{T}=4$ years (1000 days), covering the period 1.01.2006 31.12.2009. This time interval has been chosen so that it integrates in a better way the negative effects of the recent financial crisis on the evolution of the financial assets.

After the evaluation of the risk of loss for an investment it is expected for the risk exposure to be correlated with the margin capital allocated to cover the potential loss when risk is real. In the following we can see that the potential loss can be better covered when the risk exposure is determined using techniques specific to be extreme values theory.

In other words, this analysis was aimed to established if the current solvency Solvency II is closer, or not, to the insured concerning the prudential loss risk estimation. The more the loss risk will be better covered for the insured, the more the estimation will be prudent. In (Courbage et al. 2013) there is a more detailed presentation of the concept of prudentiality and its acceptability in the domain of insurance.

We must not forget that the approach of the capital allocation correlated with the risk of loss is a very complex one remaining an open problem for the researchers of the financial domain. From a principled point of view, when a regulating authority wants to improve the prudential control regime, as in the case of the development of Solvency II system, it is 
expected that this will happen through the integration in the computing methodology of the capital solvency requirements of the most prudent approaches, even if these are more complex and in consequence more difficult to implement.

The standard formula in Solvency II for calculating SCR for all (re)insurance companies that are not interested in implementing an internal model is built starting with the hypothesis that the loss distributions are normal (Sandsrtöm 2006: 214-216).

Table 1. Stucture of the hypotetical portfolio

\begin{tabular}{cllcc}
\hline Nr.crt & \multicolumn{1}{c}{ Type of bonds } & Cod ISIN & Maturity & $\begin{array}{c}\text { Buying value in Euro } \\
30.12 .2009\end{array}$ \\
\hline 1 & $\begin{array}{l}\text { Government } \\
\text { bonds - Netherland }\end{array}$ & NL0000102242 & 15.07 .2015 & 102.795 \\
\hline 2 & $\begin{array}{l}\text { Government } \\
\text { bonds - France }\end{array}$ & FR0010163543 & 25.04 .2015 & 104.505 \\
\hline 3 & $\begin{array}{l}\text { Government } \\
\text { bonds - France }\end{array}$ & FR0010216481 & 25.10 .2015 & 102.53 \\
\hline 4 & $\begin{array}{l}\text { Government } \\
\text { bonds - Belgium }\end{array}$ & BE0000973033 & 04.06 .2013 & 103.51 \\
\hline 5 & Shares & BNP PARIBAS-FR0000131104 & 55.56 \\
\hline 6 & Shares & AXA- FR0000120628 & 16.595 \\
\hline 7 & Shares & MOBISTAR- BE0003735496 & 48.0775 \\
\hline 8 & Shares & DANONE- FR0000120644 & 57.3875 \\
\hline \multirow{3}{*}{} & & \multicolumn{2}{c}{ Portofolio Value $=$} \\
\cline { 2 - 4 }
\end{tabular}

Based on the data of the hypothetic portfolio described in Table 1 we have tested the normality of the empirical loss. In parallel we have analyzed using the Anderson-Darling test the possibility of including the empirical loss distribution in one of the three domains of maximum attraction specific to the study of extreme values. We compared the VaR estimations (corresponding to the hypothesis of normality) with VaR estimations adjusted to the laws of the attraction domains significant from the statistical point of view.

In this sense, after rejecting the normality of the empirical distribution of loss, we have analyzed by the Anderson-Darling test if we can include the empirical distribution of loss in one of the three maximum domains of attraction specifics to the study of extreme values. At the end we have estimated the $99.5 \%$ extreme quantile using the parametric estimator and also the GDP estimator.

The results of this analysis are shown in Figure 2, Tables 2 and 3.

From Figure 1 we can see that the loss empirical distribution is not a normal one. Also, the estimation of the $99.5 \%$ quantile by adjusting the loss distribution with a normal one will determine a relative approximation error of about $24 \%$. This result could justify the estimation of the value at risk by the empiric estimator. Only this is not always desirable for it is known that in general an empiric estimator tends to underestimate the risk of loss. A more robust way would be to adjust the loss empirical distribution by one of the known laws of parameterization of the extreme value distribution. 


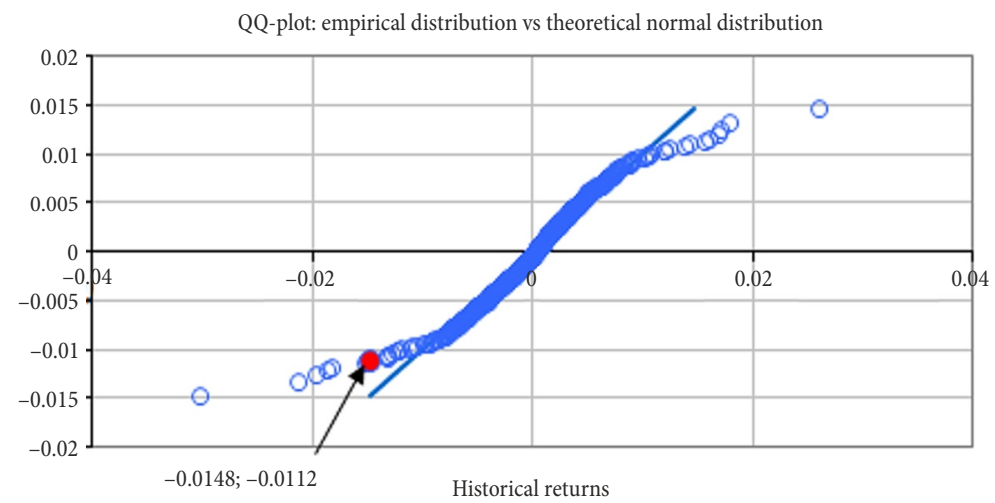

Fig. 2. Testing the normality of the historical sample

Table 2. Anderson-Darling test results

\begin{tabular}{ccc}
\hline Attraction domain & Theoretical distribution & Test result \\
\hline \multirow{3}{*}{ Fréchet $\left(\mathrm{G}_{1}\right)$} & Chi2 & Accepted \\
\cline { 2 - 3 } & Student & Rejected \\
\cline { 2 - 3 } & Pareto & Rejected \\
\cline { 2 - 3 } & Normal & Rejected \\
\cline { 2 - 3 } Gumbel $\left(\mathrm{G}_{2}\right)$ & Lognormal & Rejected \\
\cline { 2 - 3 } & Exponential & Accepted \\
\cline { 2 - 3 } & Gamma & Accepted \\
\cline { 2 - 3 } & Weibull & Accepted \\
\hline \multirow{2}{*}{ Weibull $\left(\mathrm{G}_{3}\right)$} & Uniform & Rejected \\
\cline { 2 - 3 } & Beta & Rejected \\
\hline
\end{tabular}

Table 3. Estimation of $99.5 \%$ quantile with the parametric estimator

\begin{tabular}{cc}
\hline Adjusting distribution & Value at Risk (VaR) \\
\hline Normal & 6.7464 \\
\hline Chi2 & 10.5966 \\
\hline Exponential & 9.7357 \\
\hline Gamma & 9.2088 \\
\hline Weibull & 9.2699 \\
\hline
\end{tabular}

As we can see from Table 2, by applying Anderson-Darling test to assess conformity of the loss distribution to familiar theoretical distributions, at a 5\% significance level, we can conclude that the loss empirical distribution can be adjusted by one of the following distribution laws: Chi2, Exponential, Gamma, or Weibull.

Applying the parametric estimator for determining the extreme quantile we will obtain the results from Table 3. From these results we can see that the insurer will take the most 
prudent decision if he/she will use the parametric estimation adjusted the Chi2 distribution law. This result was expected as the Chi2 law belongs to the Fréchet (G1) maximum domain of attraction, domain that is characterized as one of attraction for laws that have heavy tails.

By applying the GPD estimator, with parameters $(\xi, \beta)$ estimated by Hill and HillG (Hill Generalized) methods, in order to determine the $99.5 \%$ extreme quantile, we obtain the result: $\operatorname{VaR}(\mathrm{HillG})=9.8262, \operatorname{VaR}(\mathrm{Hill})=9.8351$. This estimation is also a prudent estimation decision.

\section{Conclusions}

It is certain that a prudential solvency regime should find the optimal poise between regulation and deregulation or between quantitative and qualitative prudential.

Following our study we can conclude that the prudential level from the Solvency II standard formula is under the level of risk exposure of an insurance company that, for example, will decide to invest in the hypothetic portfolio we have randomly created. We have also conclude that a more realistic manner to express the prudential level in the Solvency II standard formula would be the theory of extreme values, theory that offers to the insurer more alternatives for choosing a high realistic prudential level, adjusting Fréchet (G1) law (in our case Chi2), or to choose a low realistic prudential level, using the adjusted Gumbel ( $G$ 2) law (in our case Gamma or Weibull).

\section{Acknowledgements}

This research is partially supported by "Cercetare Dezvoltare Agora" (R \& D Agora) of Agora University of Oradea, Romania.

\section{Disclosure statement}

The authors have no any competing financial, professional, or personal interests from other parties.

\section{References}

Acerbi C.; Tasche, D. 2001. Expected shortfall: a natural coherent alternative to value at risk, Economic Notes 31(2): 379-388. https://doi.org/10.1111/1468-0300.00091

Acerbi, C. 2004. Coherent representations of subjective risk aversion, in G. Szegö (Ed.) Risk Measures for the 21st Century. New York: Wiley, 147-207.

Artzner, P. 1999. Application of coherent risk measures to capital requirements in insurance, North American Actuarial Journal 3(2): 11-25. https://doi.org/10.1080/10920277.1999.10595795

Bauer, D.; Zanjani, H. G. 2015 The marginal cost of risk, risk measures, and capital allocation, Management Science 62(5): 1431-1457. https://doi.org/10.1287/mnsc.2015.2190

Butaci, C. 2014. The Analysis of the influences coming from different solvency systems on the construction of the European solvency system "Solvency II", Ovidius University Annals, Economic Sciences Series 14(1): 574-579. 
Chen, Y.; Shi, Y.; Wei, X.; Zhang, L. 2014. How does credit portfolio diversification affect banks' return and risk? Evidence from Chinese listed commercial banks, Technological and Economic Development of Economy 20(2): 332-352. https://doi.org/10.3846/20294913.2014.915246

Cummins, J. D. 2000. Allocation of capital in the insurance industry, Risk management and Insurance Review 3: 7-28. https://doi org/10.1111/j.1540-6296.2000.tb00013.x

Cummins, J. D.; Phillips, R. D. 2009. Capital adequacy and insurance risk-based capital systems, Journal of Insurance Regulation 28(1): 25-72.

Courbage, C.; Rey, B.; Treich, N. 2013. Prevention and precaution, in G. Dionne (Ed.). Handbook of insurance. Second edition. New York: Springer, 185-204.

Darkiewicz, G.; Dhaene, J.; Goovaerts, M. 2003. Coherent distortion risk measures - a pitfall, Appears in Collections of Research Center Insurance, K. U. Leuven.

Dhaene, J.; Goovaerts, M.; Kaas, R. 2003. Economic capital allocation derived from risk measures, North American Actuarial Journal 7(2): 44-59. https://doi.org/10.1080/10920277.2003.10596084

Dhaene, J.; Vanduffel, S.; Quihe, T.; Goovaerts, M. J.; Kaas, R.; Vyncke, D. 2004. Solvency capital, risk measures and comonotonicity: a review, Appears in Collections of Research Center Insurance, K. U. Leuven.

Dekkers, A.; de Haan, L. 1989. On the estimation of the extreme-value index and large quantile estimation, Annals of Statistics 17(4): 1795-1832. https://doi.org/10.1214/aos/1176347396

Denuit, M.; Charpentier, A. 2005. Mathématiques de l'assurance non-vie, Tome II. Paris: Economica.

Dionne, G.; Li, J. 2011. The Impact of prudence on optimal prevention revisited, Economics Letters 113: 147-149. https://doi.org/10.1016/j.econlet.2011.06.019

Dionne, G. 2013. Risk management: history, definition, and critique, Risk Management and Insurance Review 16(2): 147-166. https://doi.org/10.1111/rmir.12016

Directive 2009/138/EC of the European Parliament and of the Council of 25 November 2009 on the taking-up and pursuit of the business of Insurance and Reinsurance (Solvency II), Official Journal of the European Union [online], [cited 25 January 2016]. Available from Internet: http://eur-lex. europa.eu/legal-content/EN/ALL/?uri=celex\%3A32009L0138.

Eiopa. 2014a. Technical Specification for the Preparatory Phase - Part I, EIOPA-14/209 [online], [cited 28 January 2016]. Available from Internet: https://eiopa.europa.eu/regulation-supervision/insurance/ solvency-ii/solvency-ii-technical-specifications.

Eiopa. 2014b. Technical Specification for the Preparatory Phase - Part II, EIOPA-14/210 [online], [cited 28 January 2016]. Available from Internet: https://eiopa.europa.eu/regulation-supervision/insurance/solvency-ii/solvency-ii-technical-specifications

Embrechts, P.; Klüppelberg, C.; Mikosch, T. 1997. Modelling Extremal Events for Insurance and Finance. Springer Verlag, Berlin.

Hill, B. 1975. A simple general approach to inference about the tail of a distribution, Annals of Statistics 3(5): 1163-1174. https://doi.org/10.1214/aos/1176343247

Hosking, J. R.; Wallis J. R. 1987. Parameter and percentile estimation for the generalized pareto distribution, Technometrics 29: 339-349. https://doi.org/10.1080/00401706.1987.10488243

Keith, J. C.; Arthur S. 2013. The theory of risk classification, in G. Dionne (Ed.). Handbook of insurance. Second edition. New York: Springer.

Kunreuther, H. 2015. The role of insurance in reducing losses from extreme events: the need for publicprivate partnerships, The Geneva Papers on Risk and Insurance - Issues and Practice 40(4): 741-762. https://doi.org/10.1057/gpp.2015.14

Markowitz, H. 1952. Portfolio selection, Journal of Finance 7(1): 77-91. https://doi.org/10.1111/j.1540-6261.1952.tb01525.x 
Markowitz H. 1959. Portfolio selection: efficient diversification of investments. New York: John Wiley \& Sons.

Partrat C.; Besson, J. L. 2005. Assurance non vie. Modélisation, simulation. Paris: Economica.

Pickands, J. 1975. Statistical inference using extreme orders statistics, Annals of Statistics 3(1): 119-131. https://doi.org/10.1214/aos/1176343003

Planchet, F.; Thérond, P. 2007. Mesure et Gestion des Risques d'Assurance. Paris: Economica.

Sandström A. 2006, Solvency: models, assessment and regulation. Boca Raton - USA: Chapman \& Hall/ CRC - Taylor \& Francis Group.

Schoenmaker, D.; Sass, J. 2016. Cross-border insurance in Europe: challenges for supervision, The Geneva Papers on Risk and Insurance - Issues and Practice 41(3): 351-377. https://doi.org/10.1057/gpp.2015.35

Smith, R. L. 1987. Estimating tails of probability distributions, Annals of Statistics 15(3): 1174-1207. https://doi.org/10.1214/aos/1176350499

Casian BUTACI is an Associate Professor at Department of Social Sciences, Faculty of Economics, Agora University of Oradea, Romania. He received her B.Sc. in Mathematics (1997), Economics (2002), Master's degree in Economics and Finance (2004) from University of Orleans, France and $\mathrm{PhD}$ in Finance (2012) from Babes-Bolyai University of Cluj - Napoca, Romania. His current research interests include different aspects of financial regulation, Solvency II and Basel II / III, capital adequacy in insurance, financial risk management.

Simona DZITAC is an Associate Professor at Energy Engineering Department, Faculty of Energy Engineering and Industrial Management, University of Oradea, Romania. She received her B.Sc. in Mathematics (2000), Energy Engineering (2005), Economic Informatics (2007) and PhD in Energy Engineering (2008). Her current research interests include different aspects of reliability, modelling, simulation, quality management, IT management. She has published 11 books/courses and materials for students and more than 80 scientific papers in journals and conferences proceedings. Her research activity includes participation in 30 grants/projects. The impact of her published works are 51 citations and h-index 4 in ISI Web of Science

Ioan DZITAC is an Information Sciences Professor at Aurel Vlaicu University of Arad and a Mathematics Professor at Agora University of Oradea - Romania. He received B.Sc. (eq.M.Sc.) in Mathematics (1977) and PhD in Information Sciences (2002) from Babes-Bolyai University of Cluj - Napoca, Romania. His current research interests include different aspects of artificial intelligence, applications mathematics in technology and economy. He has published 3 books, 12 courses and materials for students, 4 conference proceedings and more than 70 scientific papers in journals and conferences proceedings. He was an invited speaker and/or invited special sessions' organizer and chair in China (2013: Beijing, Suzhou and Chengdu, 2015: Dalian, 2016: Beijing), India (2014: Madurai), Russia (2014: Moscow) and Brazil (2015: Rio), Lithuania (2015: Druskininkai) and South Korea (2016: Asan).

Gabriela BOLOGA obtained her doctoral degree in Management in 2010 from the West University of Timisoara. She is Jean Monet Professor staring with 2007 and now she is an Associate Professor and a Vice-Rector of the Agora University of Oradea, being in charge of Financial Analysis and Project Management research and studies. She authored and co-authored more than 45 scientific papers in the field of the above subjects. Her research interests include different aspects of economical and financial studies. 